\title{
A EXPERIÊNCIA DE VER FILMES NA FORMAÇÃO INICIAL DE PROFESSORES DE EDUCAÇÃO FÍSICA
}

\author{
Fábio Machado Pinto ${ }^{1}$ \\ Lana Gomes Pereira
}

\section{RESUMO}

Este trabalho visa a registrar possibilidades de utilização da linguagem cinematográfica, enquanto conhecimento na educação do corpo. Trata-se de experiência resultante das aulas de Prática de Ensino em Educação Física, as quais culminaram com a construção coletiva de vídeo sobre as Olimpíadas desta Escola e a análise do filme Boleiros: era uma vez o futebol, de Ugo Giorgetti. Ressaltamos, porém, a importância de referencial teórico articulado com a arte cinematográfica, bem como a realização de mais pesquisas sobre a temática.

PALAVRAS-CHAVE: educação - cinema - educação do corpo - formação de professores - futebol.

"Se for essa perfeição que o futebol brasileiro vai atingir, e provavelmente atinja, organizado por firmas, companhias e corporações especializadas, certamente vai se tornar só mais um espetáculo televisivo, pretexto para que nos seus intervalos sejam colocados os comerciais, as promoções e todo o arsenal de venda que os organizadores têm à sua disposição. Porque esse tipo de futebol não precisa de torcedores, mas de consumidores. Esse futebol será também, desse modo, inútil como fonte da qual se alimentam arte e artistas."

(Ugo Giorgetti)

\section{INTRODUÇÃO}

$\mathrm{O}$ filme Boleiros: era uma vez o futebol, de Ugo Giorgetti, foi objeto de nossa reflexão durante o segundo semestre de 2003, nas aulas de Prática de Ensino de Educação Física Escolar I e II, ministradas no curso de licenciatura em Educação Física da Universidade Fede-

\footnotetext{
Professor do Departamento de Metodologia de Ensino da UFSC.

2 Professora mestranda do Programa de Pós-graduação da UFSC.
} 
ral de Santa Catarina. Este texto trata de refletir técnica e teoricamente a utilização didática do cinema nas aulas de Educação Física, mas, sobretudo na formação inicial de professores de Educação Física.

Cinema e esporte foram abordados de forma a dar novas cores à metodologia desenvolvida nesta disciplina, aplicada na forma de vídeo processo. ${ }^{3}$ Assim, iniciamos o semestre abordando o cinema a partir dos seus elementos constitutivos. Em uma oficina de Story Board, desenvolvemos técnicas de utilização da filmadora portátil, movimento e gravação, enquadramentos possíveis, aspectos relacionados à iluminação, sonorização e outros. Deste modo, abordamos o processo de produção de um vídeo amador: idéia, decupagem, pré-roteiro, roteiro e edição.

Esta oficina preparou os estagiários para o uso da filmadora, mas também para a edição de um vídeo documentário que abordasse os aspectos mais significativos da realidade educacional. Esta atividade investigativa fez parte do que denominamos tradicionalmente de Análise de Conjuntura Educacional. ${ }^{4}$

O primeiro acontecimento importante, logo no início do estágio mês de setembro de 2003 -, foi a realização de um evento denominado de Olimpíadas, que parou as atividades disciplinares do Colégio por uma semana, dando lugar a um conjunto de atividades lúdicas e esportivas.

Percebendo a importância deste evento, mobilizador de boa parte dos alunos, professores e alguns pais, lançamos o desafio de realizar uma ampla atividade de investigação do projeto de educação do corpo implícito e explícito na atividade. Assim, dividimos os 32 estagiários em 13 tarefas investigativas: três equipes ficaram responsáveis pelo registro de imagens relacionadas à abertura e encerramento do evento, as condutas disciplinares de professores, pais e alunos, as falas dos alunos e professores durante o evento, os momentos de jogos, as torcidas, a premiação etc. Foram conseguidos, também, junto a professores e exalunos, um conjunto de fitas de vídeo que registram antigas edições das olimpíadas do Colégio.

Este conjunto de imagens foi analisado e decupado pelos estagiários com o intuito, de num segundo momento, refletir sobre as possibilidades de edição de um vídeo tratando das olimpíadas, discutindo as imagens, músicas e outros sons, efeitos e montagem de um roteiro. Por fim, conseguimos editar o vídeo tendo como conteúdo os temas de investigação: a história das olimpíadas no Colégio, a disciplina dos alunos durante os

102 MACHADO PINTO, F.; PEREIRA, L. G. A experiência de ver filmes ... 
jogos, as diferenças de programação no ensino fundamental - séries iniciais e $5^{\mathrm{a}}$ a $8^{\mathrm{a}}$ séries - e no ensino médio, as solenidades de abertura e de encerramento, premiação, torcida, arbitragem, mas significativamente o que os alunos aprenderam com as olimpíadas.

Na opinião dos estagiários, o vídeo conseguiu alcançar seu objetivo ao captar um enquadramento da realidade que nos permite compreender a leitura feita por eles sobre a importância deste evento no contexto escolar. A produção e análise videográfica realizada foi potencializada por outra estratégia metodológica: apresentação, discussão e sistematização de resenhas sobre filmes e textos relacionados ao tema vídeo $e$ educação (FERRÉS, 1996).

Os filmes utilizados foram Boleiros: era uma vez o futebol, de Ugo Giorgetti, e Tiros em Colombine, de Michael Moore. À apresentação do filme precedeu-se pequena fala sobre os aspectos gerais - autor, duração, prêmios etc., indicando aos estagiários que fizessem anotações durante a apresentação, com registro das cenas mais importantes. Enquanto isso, observamos as reações do grupo durante as cenas.

Depois da exibição, buscamos lembrar coletivamente, do roteiro, da trilha sonora, dos efeitos, dos diálogos, da mensagem do filme etc. Igualmente, procuramos debater os aspectos técnicos de conteúdo e forma, as idéias principais e o que poderíamos mudar no filme. Esta discussão representou o ponto de partida para que cada aluno desenvolvesse uma resenha, a ser reapresentada em sala de aula e, posteriormente, incorporada a um texto único da turma de estágio.

Esta análise, que apresentaremos a seguir, busca desenvolver as possibilidades de reflexão sobre a cultura corporal - neste caso o Futebol - através da exibição do cinema na Educação Física escolar. Realizada no âmbito da formação inicial de professores, a tematização da arte e dos meios de comunicação tem o intuito de despertar as futuras gerações de professores para a força que estes fenômenos passaram a ter na formação do sujeito e, por conseguinte, na identidade do povo brasileiro.

Cabe ainda ressaltar que a formação em ambientes escolares, a qual se pretende atual, deve procurar aperfeiçoar seus instrumentos teórico-metodológicos para compreender as particularidades e universalidades relacionadas às culturas que se entrelaçam nas salas de aula, nas quadras esportivas ou nos pátios escolares. A análise que segue é uma tentativa coletiva de trazer para o contexto da Educação Física aspectos 
importantes do futebol, fenômeno nacional que inebria milhões de corações e alcança todas as dimensões do ser humano. A análise coletiva de Boleiros: era uma vez o futebol, teve como objetivo identificar os principais componentes do filme, bem como as possibilidades de utilização do cinema nas aulas de Educação Física.

\section{EDUCAÇÃO DO CORPO E CINEMA}

Segundo Duarte (2002, p. 14), nota-se que em "sociedades audiovisuais" como a nossa, o acesso ao cinema e, indo mais além, o domínio da linguagem cinematográfica nas suas singularidades, podem auxiliar e enriquecer a compreensão do corpo e sua educação na escola. E se compreendermos a educação imersa numa sociedade audiovisual, a interpretação filmística e sua apropriação adquirem relevância dentre os saberes escolares.

Algumas teorias entendem a educação do corpo de forma fragmentada e dicotômica, contudo, novas reflexões, como as de Vaz (1999), Silva (2002) entre outros, pensam o corpo de forma integrada e nas suas dimensões social, histórica, econômica, política, cognoscitiva, cultural e artística, mas também psicológica, biológica e física. A Educação Física necessita abrir espaço para todas estas expressões, para que o professor/mediador possibilite ao aluno/sujeito a ampliação dos modos específicos de apropriação da realidade.

De acordo com Melo (2002), destacam-se questões sobre a educação para/pela sensibilidade e o sentido cognoscitivo, para então promovermos olhares mais tolerantes, potencialmente capazes de refletir a questão do prazer, por exemplo. Ainda, conforme o autor, a educação estética precisa ser vista em sua articulação com a ética, visando a um modo específico de apropriação da realidade, no qual o sentido cognoscitivo se destaque.

Salientamos, não apenas a enorme presença das questões do corpo no cinema, ${ }^{5}$ mas também porque vivemos uma época em que a imagem, principalmente na educação do corpo, vem ocupando na sociedade brasileira, lugar privilegiado. Estudar o cinema e seus imperativos educacionais pode nos ajudar a entender a realidade do tempo presente, bem como as possibilidades de superação dos seus principais impasses sociais, políticos e culturais.

104 MACHADO PINTO, F.; PEREIRA, L. G. A experiência de ver filmes ... 
Assim como no cinema, o corpo ${ }^{6}$ também tem ocupado um espaço maior na sociedade contemporânea, ao mesmo tempo em que aumenta o número de abordagens teóricas - antes limitadas à área biológica - preocupadas com a temática. $\mathrm{O}$ corpo e a educação corporal têm sido longamente estudados por disciplinas como antropologia, filosofia e sociologia, o que, de certa forma, facilita o estudo da sua presença no âmbito do cinema. No entanto, esta tarefa, ainda que importante, foi realizada por poucos pesquisadores. Cinema e educação do corpo são, portanto, fenômenos que ainda não tiveram a devida atenção no meio acadêmico.

\section{Boleiros em foco}

Boleiros: era uma vez o futebol tende para o humor e a leveza mesmo quando é sério, na tentativa de seguir a essência do futebol, onde figuram a firula, o drible, o toque de calcanhar, o gol de letra etc. Os temas são abordados com ilustrações do tipo vinheta: o lance que ficou na memória, a frase de um jogador, o momento particularmente empolgante de um campeonato, a atuação de um jogador ou juiz. O filme empolga pela forma como foi montado, recriando a maneira brasileira de contar os fatos do futebol. Mas de um dado futebol, que aos poucos deixa de existir, como lembra o próprio autor:

O que está surgindo diante de nossos olhos, e que talvez nos seja dado descrever e interpretar, é um novo futebol amoldado, domado e amansado pelas regras de um admirável mundo novo que também está se consolidando diante de nossos olhos (GIORGETTI ET AL., 1999, p. 18).

Parece muito mais uma crítica contundente, mas também saudosista, de um tempo no qual o futebol parecia aproximar os sujeitos, envolvendo-os afetivamente de forma a proporcionar uma experiência de lazer mais completa. Torcida, árbitros, treinadores e jogadores eram envolvidos muito mais pelo prazer de ver e jogar futebol do que pelos interesses que tem direcionado o futebol na atualidade.

Não teria pessoalmente nada contra as mudanças que vejo surgir, todas elas movidas pelo dinheiro de patrocinadores e investidores, se algumas delas não agissem para extinguir algumas virtudes que eu acho funda- 
mentais para o futebol e vitais para que este esporte continue sendo objeto de interesse de qualquer artista. Entre elas a irracionalidade e por consequiência, a paixão, o imprevisível, o imponderável e o inesperado (GIORGETTIETAL., 1999, p. 18).

O roteiro mostra alguns amigos, ex-boleiros, ex-árbitros e amantes da bola que se reúnem num bar para tomar cerveja e relembrar antigas estórias. Esta cena torna-se o foco principal do filme, somente deixada de lado quando as histórias por eles contadas surgem na tela como momentos imaginados. A principal mágoa, e tema do bate-papo, é o fato de se encontrarem em uma situação financeira difícil, mas também porque não brilham na mídia e nos gramados como no passado. Ao contrário, muitas vezes são humilhados, vistos exercendo atividades precárias, ou ainda pior, lutando com dificuldade pela sobrevivência.

O ponto comum em todas as histórias fictícias (porém facilmente observáveis no mundo real do futebol) talvez seja o fato de revelar a difícil tarefa que é chegar ao lugar desejado, se manter no topo, e, principalmente, o desafio de continuar a vida após a curta carreira de atleta. ${ }^{7}$

O filme ajuda a refletir sobre as glórias e as frustrações, confusões e trapaças, rituais e superstições, preconceitos que permeiam o universo futebolístico. Este universo é permeado de mitos como "quem é bom já vêm do berço", "craque não se faz já nasce pronto" ou "quem conhece sabe quem vai ser boleiro só pelo caminhar", e outros. Estes mitos ajudam, em grande parte, a consolidar uma racionalidade inatista e passiva, criando uma espécie de aura em torno dos ídolos como se fossem escolhidos por algo superior.

Entre outras coisas, isso contribui para a promoção da ilusão criada em milhões de garotos que sonham tornarem-se grandes estrelas. $\mathrm{O}$ futebol talvez seja uma das poucas formas de mobilidade social prometida às classes populares, por isso muitos garotos e garotas desejam ser profissional da bola e fazer sucesso como as estrelas esportivas. Não são poucas as dificuldades encontradas pelos meninos que querem ser um grande jogador. Existe um verdadeiro funil que torna o estrelato do futebol algo só comparado ao concurso lotérico.

Contudo, o sonho de ser jogador contamina quase todo garoto, ocupando espaço cada vez maior nos jornais e telejornais, em filmes, nos

106 MACHADO PINTO, F.; PEREIRA, L. G. A experiência de ver filmes ... 
horários nobres da TV, com informações e propagandas publicitárias. Todo torcedor passa a fazer parte deste grande espetáculo, não só como torcedor, mas consumidor de promessas de ser que nunca serão cumpridas.

Muitas vezes temos como ídolos pessoas que nem parecem humanas de tão perfeitas. Achamos que as conhecemos e não paramos para pensar o que realmente é verdade de tudo aquilo que aparece na mídia sobre elas. ${ }^{8}$

O sonho de se tornar um craque vem sendo cada vez mais notado entre jovens e crianças, principalmente quando trata-se de famílias pobres, que vêem no futebol a esperança de "melhorar de vida".

Não precisamos consultar os dados estatísticos para saber que para cada Ronaldinho existem milhares de atletas cuja situação econômica é bastante precária.

Garotos tentam de todo o modo galgar esta pirâmide, a fim de escapar da dura vida que a pobreza impõe a estas pessoas. ${ }^{10}$

O jogador de futebol é valorizado quando ganha jogos e campeonatos, mas extremamente pressionado, e até execrado, quando perde ou se machuca. Parece mesmo que o futebol não perdoa quem fracassa, é a vitória ou o esquecimento. O esquecimento talvez seja o pior dos temores dos jogadores. Uma indústria de corpos descartáveis, na qual poucos alcançam o estrelato e a eternidade tão buscada.

Durante a vida futebolística, os corpos dos atletas são sugados na sua máxima possibilidade. Em muitos casos, resultados de treinamentos mal aplicados e por profissionais despreparados acabam encurtando a carreira profissional desses jogadores. O treinamento para o futebol profissional exige muito dos atletas, somado às viagens e concentrações que tomam todo o tempo do jogador. Cansados e com pouco tempo, os jovens acabam afastando-se das escolas. Isto, aliado à falta de apoio nos clubes, que não pensam na formação intelectual de seus atletas, faz do futebol um ambiente que não combina com a educação formal. Educar o corpo nos clubes futebolísticos parece se contrapor à educação escolar, gerando problemas para esses jovens num futuro em que o futebol deixa de ter uma função prioritária. 
Boleiros: era uma vez o futebol não trata da falta de perspectiva da maioria dos jogadores de futebol, com baixos salários, muitas vezes atrasados, sem amparo médico e social, tendo que jogar muitas vezes machucado, sujeito a intervenções médicas mal feitas etc. $\mathrm{O}$ filme não fala das peneiras e da promessa a milhares de crianças que nunca serão cumpridas.

Mas Boleiros: era uma vez o futebol nos ajuda a pensar, com elementos relacionados à importância da formação escolar na vida dos jogadores, que tendo findado a carreira futebolística acabam na penúria. Se a carreira futebolística impõe dificuldades à participação dos jovens no ensino regular, neste caso deveríamos levar o Estatuto da Criança e do Adolescente mais a sério e exigir que as escolinhas fossem orientadas pelo princípio do trabalho educativo, atividades esportivas durante, no máximo, meio turno e obrigatoriedade da frequiência no ensino formal.

Para os personagens do filme, a única saída para os ex-jogadores é o próprio futebol, retornar como treinadores, comentaristas, técnicos, professor em escolinhas, entre outros. Do contrário, acabam em situações complicadas de sobrevivência.

Os atletas devem ter a consciência de que o esporte é uma carreira curta, limitada pela idade, e que precisam se preocupar e planejar seu futuro, caso contrário correm o risco de ficar sem perspectivas e na miséria. ${ }^{11}$

Por fim, o filme pode ser um ponta-pé inicial para refletir sobre a cultura corporal, sobretudo a falta de uma política ou de um programa social bem estruturado, voltado ao esporte brasileiro. Ou ainda, sobre o papel da Educação Física Escolar no estudo e esclarecimento sobre a vida dos trabalhadores da bola. Possibilidades de ensino que podem contribuir para a formação destes possíveis atletas, com saberes relacionados ao treinamento esportivo, aos seus direitos trabalhistas, noções de política e esporte, sexualidade e esporte, questões históricas, técnicas e táticas do futebol, entre outras, mas principalmente das reais possibilidades de se chegar a ser um nome de destaque nos campos de futebol e da força que estes nomes exercem na formação da subjetividade dos sujeitos.

O fato é que precisamos mostrar para as crianças que a educação é o caminho, o futuro, e o esporte pode ser o grande auxiliar ou até mesmo a razão de ser do estudo. ${ }^{12}$

108 MACHADO PINTO, F.; PEREIRA, L. G. A experiência de ver filmes ... 


\section{EXPERIÊNCIA DE VER FILMES: ALGUMAS CONSIDERAÇÕES SOBRE CINEMA NA ESCOLA}

O cinema pode ser compreendido por meio de duas dimensões: cinema enquanto produto e constituinte da Indústria Cultural e cinema enquanto arte. Estas duas dimensões podem ser identificadas como antagônicas, mas muitas obras que são culturas de massa possuem valor estético, como as músicas de Madona, os filmes de Spielberg etc. Temos que o cinema, assim como o esporte competitivo, são fenômenos sóciohistórico-culturais que possuem como objetivo, atualmente, promover o espetáculo numa sociedade administrada.

Segundo Adorno e Horkheimer (1985, p. 138),

quanto menos promessas a Indústria Cultural tem a fazer, quanto menos ela consegue dar uma explicação da vida como algo dotado de sentido, mais vazia torna-se necessariamente a ideologia que ela difunde. Mesmo os ideais abstratos da harmonia e da bondade da sociedade são demasiado concretos na era da propaganda universal. Pois as abstrações são justamente o que aprendemos a identificar como propaganda. A linguagem que apela apenas a verdade desperta tão-somente a impaciência de chegar logo ao objetivo comercial que ela na realidade persegue. A palavra que não é simples meio para algum fim, parece destituída de sentido, e as outras parecem simples ficção, inverdades.

Este fenômeno, cinema - produto e constituinte da Indústria Cultural -, está pautado em uma ideologia de esfera liberal, por meio da qual se torna mecanismo de controle da lógica dominante, gerando e desconstruindo necessidades nos espectadores, produzindo, dirigindo e disciplinando os gostos dos consumidores, que aos poucos vão se desacostumando de sua subjetividade. Com a subjetividade danificada, os sujeitos passam a exigir uma diversão cada vez menos complexa ou reflexiva. ${ }^{13}$

Como consequiência deste processo, que também é conseqüência da difusão dos movimentos de massa, temos que o cinema conseguiu transformar os sujeitos de uma forma tão indiferenciada, em funções sociais, que as vítimas não se lembrando mais de nenhum conflito, se comprazem com sua própria desumanização como algo humano, uma felicidade aconchegante, faz com que os consumidores sejam objetos passivos, alterando a forma de percepção do sujeito. 
Os sujeitos já não conseguem distinguir mais os produtos da Indústria Cultural das obras de arte, pois aquilo que caracterizava a obra artística, como arte, a concretude da relação sujeito-objeto por meio da contemplação, não é mais permitido. Segundo Benjamim (1969), o objeto é retirado de seu invólucro, o que permite a destruição da aura dos objetos artísticos, aumentando e acelerando as possibilidades de o sujeito não resistir à vontade de possuir o objeto, porque na sociedade capitalista as obras de arte vêm se tornando antes de tudo mercadorias.

Com relação ao cinema, a obra de arte surge na montagem fragmentada da reprodução de um acontecimento. Chamaríamos isso de forma. A partir destas considerações passamos a observar que o cinema pode ser arte, entretanto é necessário esclarecer que o movimento que tentaremos provocar é de uma dialética entre forma e conteúdo para entendermos as ambigüidades deste fenômeno. Assim, temos, segundo Silva (2002), o cinema para Adorno ganha status de arte quando

a estética do filme deverá antes recorrer a uma forma de experiência subjetiva com a qual se assemelha apesar da sua origem tecnológica, e que perfaz aquilo que ele tem de artístico. [...] O filme seria arte enquanto reposição objetivadora dessa espécie de experiência [...]; o filme emancipado teria de retirar o seu caráter a priori coletivo do contexto de atuação inconsciente e irracional, colocando-o a serviço da intenção iluminista. [...]; A produção cinematográfica emancipada não deveria mais [...] confiar irrefletidamente na tecnologia do fundamento do métier [...]; como seria bonito se na atual situação, fosse possível afirmar que os filmes seriam tanto mais obras de arte quanto menos eles aparecessem como obras de arte (SILVA, 2002, p. 102-107).

Contudo, o que se faz presente hoje, segundo Adorno (1985), é o fim da experiência. Parece ser tarefa quase impossível nos distanciarmos do objeto, para que possamos refleti-lo, pois, a experiência coletiva contemporânea que vivemos é de um totalitarismo que liquida com o individual.

Citando Bourdieu, Duarte (2002, p. 13) adverte que

a experiência das pessoas com o cinema contribuiu para desenvolver o que se pode chamar de "competência para ver" isto é, certa disposição, valorizada socialmente, para analisar, compreender e apreciar qualquer história contada em linguagem cinematográfica. Entretanto, o autor assinala que essa competência não é adquirida apenas vendo filmes; a at-

110 MACHADO PINTO, F.; PEREIRA, L. G. A experiência de ver filmes ... 
mosfera em que as pessoas estão imersas - que inclui, além da experiência escolar o grau de afinidade que elas mantêm com as artes e a mídia é o que lhes permite desenvolver determinadas maneiras de lidar com os produtos culturais, incluindo o cinema.

Ao refletir sobre essas múltiplas dimensões, percebemos que o cinema que chega na escola em grande medida atende aos interesses da lógica dominante. Assim, a interpretação filmística necessita de um referencial teórico e de elementos metodológicos capazes de identificar a forma e o conteúdo do filme que contribua para uma educação estética, tendo a arte como conhecimento. ${ }^{14}$

As artes e as linguagens estéticas abrem espaço para a experiência estética e a ampliação da compreensão do real. Entretanto, esbarramos numa cultura escolar onde impera a superficialidade, o comodismo e a falta de perspectiva. Os currículos e o fazer são comprometidos por uma instituição que se limitou a cumprir o simples papel de incluir, quando na verdade ela possui uma carga reprodutora e excludente, já que se baseia numa hierarquização de saberes que andam afastados da cultura popular.

A escola está separada da vida, das teorias dos conceitos, das artes. A produção cinematográfica neste contexto pode significar uma tentativa de conciliar a escola com outras linguagens, não só as imagéticas, mas também, a sonora, a auditiva, a olfativa, as táteis, as gustativas, mais próximas da complexidade da vida.

Para Goulart (2003), é possível reinventar a escola através do cinema porque este permite uma reflexão sobre o ser humano na sua universalidade. Ao considerar as condições sociais como elementos indispensáveis para criarmos um espaço de diálogo de conhecimentos, Goulart (2003, p.159) reitera que a educação escolar deve propor uma espécie de passagem do "cotidiano da escola para a educação do cotidiano".

\section{CONCLUSÃO}

A preocupação deste artigo é refletir e compreender as possibilidades de articulação entre um determinado tipo de educação e um determinado tipo de cinema. Não estamos propondo a escolarização ou didatização do cinema, pois este é importante para a educação dos educadores, independentemente de ser uma fonte de conhecimento e de servir como recurso didático-pedagógico. 
A relevância da articulação entre cinema e educação se dá pela formação para a sensibilidade, para desenvolver as capacidades cognoscitivas de alunos e educadores. Para Duarte (2002, p. 17), "ver filmes é uma prática social tão importante do ponto de vista da formação cultural e educacional das pessoas, quanto a leitura de obras literárias, filosóficas, sociológicas e tantas mais."

A partir desta perspectiva realizamos uma experiência com os alunos da Prática de Ensino em Educação Física Escolar, na qual pudemos perceber o quanto a imagem em movimento e som vem ocupando espaço cada vez mais significativo na formação do sujeito, ou poderíamos falar de uma semiformação dos jovens.

O cinema indústria contribui para uma educação do corpo pautada na conformação de padrões estéticos preestabelecidos por uma sociedade imersa no mundo que vive de aparência. Entretanto cabe ressaltar que Adorno e Horkheimer (1985) vêem que a Indústria Cultural produz o antídoto do seu próprio veneno e é por dentro dela que o cinema enquanto arte se expressa de forma tímida e quase imperceptível. Para isso é preciso desmistificar o cinema e sua linguagem, que camufla a contradição imagem, movimento e som em prol da confusão entre o que é real e o que não é real, causando no consumidor uma confusão entre a vida e o filme, o espectador confunde o cotidiano como prolongamento do filme que está em cartaz.

Assim, para utilizarmos a linguagem cinematográfica enquanto conteúdo, precisamos ter em mãos uma teoria estética que nos possibilite realizar análises filmísticas que tematizem o "corpo" e a educação deste. Seja, desmistificando o cinema enquanto produto e constituinte da indústria cultural, seja promovendo o cinema enquanto arte.

The experience of watching films in the early stages of education programs for physical education teachers

\begin{abstract}
This research work aims at registering the possibilites of using the language of cinema as a knowledge in body education. This experience was conducted during Physical Education Teaching Practices classes which ended with the collective making of a video about school olympics and the analysis of the film Boleiros, by Ugo Giorgetti. We would like to highlight the importance of the theoretical reference in articulation with cinematic art, as well as the need to conduct further research on the theme.

KEY WORDS: education - cinema - body education - teacher education - football.
\end{abstract}

112 MACHADO PINTO, F.; PEREIRA, L. G. A experiência de ver filmes ... 


\section{La experiencia de ver películas en la formación inicial}

de profesores de educación física

\section{RESUMEN}

Este trabajo visa registrar posibilidades de utilización del lenguaje cinematográfico, con relación al conocimiento en la educación del cuerpo. Se trata de experiencia resultante de las clases de Práctica de Enseñanza en Educación Física, las cuales culminaron con la construcción colectiva de vídeo sobre las Olimpíadas de esta Escuela y el análisis de la película Boleiros, de Ugo Giorgetti. Sin embargo, resaltamos, la importancia de referencial teórico articulado con el arte cinematográfica, así como también la realización de más investigaciones sobre la temática.

PALABRAS-CLAVE: educación - cine - educación del cuerpo - formación de profesores - fútbol.

\section{NOTAS}

3 Cf Ferrés (1996). O videoprocesso caracteriza-se pelo envolvimento dos alunos no processo de produção do vídeo. Os alunos passam a sujeitos ativos, planejando, registrando imagens, elaborando roteiros, avaliando. Assim, implica em participação, criatividade, compromisso e dinamismo dos alunos. O vídeo pode se converter num brinquedo, um instrumento lúdico que possibilita um aprendizado criativo do trabalho em grupo. A pesquisa é outra estratégia pedagógica que pode ser enriquecida pelo videoprocesso, tanto na captação das informações, quanto na sua socialização. A utilização desta modalidade pode ser reinventada a cada dia.

4 Cf Pinto, Vaz e Sayão (2002). Trata-se de uma etapa inicial de estágio, onde os estagiários são mediados a realizarem uma primeira investigação tendo como instrumentos a entrevista, a observação participante, os registros de caderno de campo e videográfico e as análises de documentos.

5 Melo (2003), ao analisar 3416 filmes de longa metragem brasileiros, verificou que 134 tocam o tema do esporte. Isso pode contribuir significativamente para entendermos como esporte e cinema se constituem, interligados, como fenômenos da modernidade. O autor busca responder algumas questões sobre a relação lazer e cinema: que papel deve ocupar o profissional do lazer neste contexto, ou, como educar pelo e fundamentalmente para o cinema, como superar a visão superficial, dispersa e casual para outra, crítica e orientada. 
6 Vários dos trabalhos do Núcleo de Estudos e Pesquisa Corpo, Educação e Sociedade têm se ocupado da temática, que vem sendo trabalhada, internamente, nos grupos de estudo "Escola" e "Indústria Cultural".

7 Parte da resenha do estagiário Caio Casseli Martins (2003).

8 Parte da resenha da estagiária Patrícia Domingos dos Santos.

9 Parte da resenha da estagiária Helena Pereira.

${ }^{10}$ Parte da resenha do estagiário Cleber Pereira Heimberg.

${ }_{11}$ Parte da resenha da estagiária Gabriela Medeiros de Almeida.

${ }_{12}$ Parte da resenha da estagiária Greice K. Cipriane.

13 A subjetividade danificada vem se construindo nesta sociedade, porque na contemporaneidade, o conceito (razão) é banalizado, reificado, o sujeito é educado pelas informações e acaba tendo uma pseudoformação. A experiência, nesta sociedade, não é mais permitida, o tempo é o do efêmero, um tempo acelerado. E o conceito de vivência vem como reação a este fenômeno.

${ }^{14}$ A arte só se realiza enquanto conhecimento quando ela é criação, e para isso ela prioritariamente não pode ser cópia de uma determinada realidade.

\section{REFERÊNCIAS}

ADORNO, T. W.; HORKHEIMER, M. Dialética do esclarecimento: fragmentos filosóficos. Rio de Janeiro: Jorge Zahar, 1985.

BENJAMIN, V. A obra de arte na era da sua reprodutibilidade técnica. In: A idéia do cinema. Rio de Janeiro: Civilização Brasileira, 1969.

DUARTE, R. Cinema \& educação. Belo Horizonte: Autêntica, 2002.

FERRÉS, J. Vídeo educação. 2. ed. Porto Alegre: Artes Médicas, 1996.

GIORGETTI, U.; SOCRATES e MURAD, M. Boleiros, futebol e cinema. In: DA COSTA, M. R. (org.) et al. Futebol: espetáculo do século. São Paulo: Musa, 1999.

GOULART, C. Reinventando diálogos, vínculos, razões e sensibilidades. In: TEIXEIRA, I. A.; LOPES, J. S. M. (Orgs.) A escola vai ao cinema. Belo Horizonte: Autêntica, 2003.

MELO, V. A. Memórias do esporte no Cinema. Sua presença em longas metragens brasileiros. In: Seminário Lazer em Debate CELAR/

114 MACHADO PINTO, F.; PEREIRA, L. G. A experiência de ver filmes ... 
EEFFITO/UFMG, 3, Belo Horizonte, 2002. Disponível em: <http:// www.lazer.eefd.ufrj.br/producoes/producoes.html>. Acesso em: 2003.

MELO, V. A. Análise da produção cinematográfica. O lazer e a animação cultural. RBCE. Disponível em: <http://www.lazer.eefd.ufrj.br/ producoes/producoes.html>. Acesso em: 2003.

PINTO, F. M.; VAZ, A. F.; SAYÃO, D. T. (Orgs.). Educação do corpo e formação de professores: reflexões sobre a prática de ensino de educação física. Florianópolis: UFSC, 2002.

SILVA, A. M. Corpo, ciência e mercado: reflexões acerca da gestação de um novo arquétipo da felicidade. Florianópolis: EDUFSC, 2002.

VASQUEZ, A. S. As idéias estéticas de Marx. Trad. de Carlos Nelson Coutinho. 2. ed. Rio de Janeiro: Paz e Terra, 1978.

VAZ, A. F. Treinar o corpo, dominar a natureza: notas para uma análise do esporte como base no treinamento corporal. In: Cadernos CEDES 48, ano 19, Campinas: CEDES, 1999. p. 89-108.

Recebido: 30 de setembro de 2004

Aprovado: 20 de outubro de 2004

Endereço para correspondência

UFSC - Centro de Ciências da Educação

Departamento de Metodologia de Ensino

Cidade Universitária - Centro de Educação - Sala 215

Trindade - Florianópolis - SC

CEP $88000-000$

E-mail: fabiobage@terra.com.br 
